\title{
INTERDISCIPLINARIDADE NO ENSINO EM ADMINISTRAÇÃO: VISÃO DE ESPECIALISTAS E COORDENADORES DE CURSOS DE GRADUAÇÃO
}

\author{
INTERDISCIPLINARITY IN MANAGEMENT COURSES: \\ THE OPINIONS OF UNDERGRADUATE PROGRAM SPECIALISTS \\ AND COORDINATORS
}

Recebido em: 19/06/2015 - Aprovado em: 31/08/2015

Avaliado pelo sistema double blind review

Editora Científica: Manolita Correia Lima DOI: $10.13058 /$ raep.2015.v16n4.384

\section{LUCIANA ORANGES CEZARINO lcezarino@gmail.com UNIVERSIDADE FEDERAL DE UBERLÂNDIA}

\section{HAMILTON LUIZ CORRÊA UNIVERSIDADE DE SÃO PAULO}

\begin{abstract}
RESUMO
Cursos de graduação em administração estão inseridos em contextos turbulentos e apresentam dificuldades em gerir recursos e competências de diferentes naturezas. Uma das questões mais enfáticas é a capacidade de aperfeiçoar a formação do estudante para os desafios da profissão de gestão. Sintomas como dissociação entre teoria e prática, falta de sequência lógica de conteúdo, excesso de aulas expositivas e incapacidade para desenvolver no aluno as habilidades demandadas pelo mercado são sempre lembrados nas críticas ao trabalho realizado por eles. Por sua vez, a interdisciplinaridade, tratada como promoção controlada de relações entre diferentes conteúdos disciplinar, hoje considerada mais processo que produto (FAZENDA, 1991; 2006), visa desenvolver o pensamento complexo capaz de entender a realidade sistêmica, relacionando elementos presentes em diferentes áreas. Por meio das práticas interdisciplinares, o ensino em Administração poderia superar os problemas de formação apresentados, ou ao menos, reduzi-los. Dessa forma, este trabalho tem como objetivo apresentar a visão de especialistas, membros de grupos de pesquisa em interdisciplinaridade, e coordenadores de cursos de administração por meio de entrevistas pessoais e método Delphi com formulário preenchido online. Como resultados, foi possível afirmar que os especialistas não distinguem a interdisciplinaridade aplicada em diferentes contextos da aplicada no ensino em administração; e que, os coordenadores de cursos apoiam a ideia, mas têm dificuldades estruturais e organizacionais de realiza-las. Por fim, o ensino em administração na visão de ambos carece de maior interdisciplinaridade, mas para que isso mude seria necessária uma reforma na estrutura das matrizes curriculares dos cursos, como também empreendimento dos professores com maior foco à graduação em detrimento da pós-graduação além de uma inflexão dos métodos didáticos utilizados em sala de aula, tornando-os mais centrados no aluno do que intensos na figura do professor, eliminando o excesso de aulas expositivas. Iniciativas que proporcionem o pensamento sistêmico sejam na extensão ou em casos de estudo podem fortalecer a interdisciplinaridade no ensino em administração.

Palavras-chave: Ensino em Administração; interdisciplinaridade; escolas de negócios; método Delphi.
\end{abstract}

\section{ABSTRACT}

Undergraduate management courses find themselves in turbulent contexts and facing difficulties in generating resources and competencies of different natures. One of the biggest problems is the capacity to refine students' education in line with the challenges that arise in the management profession Symptoms such as the disassociation between theory and practice, the lack of a logical sequence of content, an excess of lectures and the inability to develop students' skills in market demand are always mentioned as criticisms. Interdisciplinarity, however, treated as the controlled promotion of relationships between different disciplinary contents and currently considered more as a process than a product (fazenda, 1991; 2006), aims to develop a complex thinking able to understand the systemic reality and relating elements found in different areas. Using interdisciplinary practices, teaching in management could overcome, or at least reduce, the issues present in its courses. Thus, the objective of this paper is to present the point of view of specialists, interdisciplinarity research group members and management course administrators through personal interviews and the Delphi method that employed an online questionnaire. The findings show that specialists do not distinguish between interdisciplinarity applied in management teaching to that in different contexts, while course administrators are supportive of the idea, but face structural and organizational difficulties to put it into practice. Management teaching is seen by both these groups to lack greater interdisciplinarity, but in order to change this a reform is needed in curricular structures, as well as an effort by professors with a stronger focus on post-graduate degree, to the detriment of graduate degree courses. In addition, an inversion is required in the didactic methods used in the classroom, making them more student-centric than teacher-focused and thus eliminating the excess of lecture classes. Initiatives that provide systematic thinking, whether in their extent or in case studies, can also strengthen interdisciplinarity in management teaching.

Keywords: management teaching; interdisciplinarity; business schools; Delphi method. 


\section{INTRODUÇÃO}

A formação dos trabalhadores dentro dos moldes tayloristas no início do século $\mathrm{xx}$ valorizava a especialização. $\mathrm{O}$ trabalhador era mero fator de produção, não tomando decisões e agindo mecanicamente. Treinar trabalhadores era sinônimo de ensinar o funcionamento das organizações, o que, como consequência da divisão dos conhecimentos, era uma tarefa relativamente fácil (CEZARINO; HEARNOUX JUNIOR; CORREA, 2OI2).

A maneira encontrada de dividir o ensino foi fragmentar a organização em partes menores para que ela pudesse ser compreendida, descobrir o detalhamento das partes e esperar que o aluno soubesse conectá-las, entendendo as consequências das relações entre elas. Assim, esperava-se que um indivíduo estivesse apto a administrar. A visão de mundo mecanicista e dividido, enfatizada pela ciência moderna, não permitiu que se destacasse a complexidade da nova realidade, levando a fragmentações disciplinares permanentes, na tentativa de esmiuçar a realidade. Contudo, o processo de globalização e a trajetória da economia de empresas dos séculos xx e xxI mostraram o esgotamento desse modelo de ensinar, pincipalmente na administração de empresas (CEZARINO, 20I3).

Por sua vez, corporações modernas e de alta tecnologia abandonaram em parte o modelo taylorista-fordista de produção ou pelo menos não o consideram mais a única estratégia para a solução de seus problemas de gestão. A realidade, principalmente das organizações, é um todo sistêmico e multidimensional em que todos os seus aspectos estão ligados e são interdependentes, fazendo com que todo o significado passe a influenciar e ser influenciado pelo contexto. Os novos modelos flexíveis e orgânicos de gestão fazem com que os trabalhadores tenham de se reaproximar do conhecimento sobre seu saber fazer, do qual o modelo taylorista / fordista o distanciou (GUSDORF, 2006).

Inseridas nessa realidade, as escolas de Administração atravessam momentos árduos. O avanço tecnológico da informação, a mudança de comportamento do estudante, as avaliações institucionais, a pressão por produtividade de pesquisa e os rankings de comparação contribuem 
para o ambiente turbulento em que elas se encontram. Tal ambiente exige profissionalização urgente de sua gestão como em qualquer outra Organização (CEZARINO; HEARNOUX JUNIOR; CORREA, 2OI2).

Espera-se que a escola desperte no aluno o pensamento crítico e sistêmico capaz de fazer dele um explorador de soluções para os problemas empresariais complexos que o aguardam no exercício da profissão, livres de soluções específicas em relação a um conteúdo ou disciplina. Em face disso os cursos, muitas vezes, se mostram inertes diante das mudanças no mundo dos negócios ou no mínimo estão atrasadas em relação à necessidade de introdução de novas técnicas e métodos para que desempenhem bem sua função (POLDONY, 2009; BENNIS, 2005).

Além disso, embora pareça distante, a crítica à formação fragmentada evidencia o esgotamento do ensino de Administração pela sua transformação em mera sequência de conteúdos. No entanto, é nesse ambiente universitário que se abre uma oportunidade para que se supere o excesso de especialização que limitou a formação desses profissionais. Num momento como este, é fundamental que se possa contar com administradores públicos ou de empresas privadas capazes de romper com as antigas regras de um país onde concorrência e risco não faziam parte dos negócios. Os administradores devem ter visão para (des)regular com isenção os mercados que se abrem, sendo capazes de otimizar o capital investido nesses mercados (NICOLINI, 2003, p.45).

Nesta linha, a interdisciplinaridade surge como uma possibilidade de enfrentamento destes desafios. Nascida na França, o termo se desenvolveu como ideia a ser investigada a partir do final dos anos 1960, fazendo parte das investigações acadêmicas até a atualidade.

O discurso da interdisciplinaridade é atualmente utilizado em diversos âmbitos como saúde (CAMPOS; DOMITTI, 2007; MINAYO; SOUZA, I998), educação (FAZENDA, I99I; BAIRON, 2002; ETGES, I995) e organizações (SERVA; ANDION, 2006; DEMAJOROVIC; DA SILVA, 20I2). Portanto, apenas desenvolver análise sob a ótica do campo da administração seria um erro. O esclarecimento do conceito da interdisciplinaridade no ensino das escolas de Administração é o ponto de partida para outros estudos. 
Somente após esclarecer o conceito, consultando pesquisadores e especialistas em interdisciplinaridade e entrevistando coordenadores de curso, foi possível estabelecer as dimensões deste conceito. De posse das dimensões, foi possível questionar: Qual a visão da interdisciplinaridade no ensino dos cursos de graduação em escolas de Administração sob a ótica dos especialistas e coordenadores de curso? 


\section{OBJETIVOS E MÉTODO}

Desta forma, tem-se como objetivo geral deste trabalho captar a visão de especialistas que compõem grupos de pesquisas cadastrados pelo diretório do Conselho Nacional de Desenvolvimento Científico e Tecnológico (CNPq) e coordenadores de curso de administração em duas universidades paulistas a respeito de suas visões sobre interdisciplinaridade no ensino em Administração.

Esta pesquisa tem natureza exploratória e caráter qualitativo. Cooper e Schindler (2003) consideram a pesquisa exploratória particularmente útil quando o pesquisador não tem uma ideia clara dos problemas que vai enfrentar durante seu estudo. Por meio da exploração, o pesquisador desenvolve conceitos de forma mais clara, estabelece prioridades, desenvolve definições operacionais e melhora o planejamento final da pesquisa.

Desta forma, a primeira etapa a ser compreendida pela pesquisa seria entender as diferenças entre a interdisciplinaridade em seu conceito puro, teórico, e a interdisciplinaridade no ensino de Administração, nos cursos de graduação. Não se considerou assumir que a interdisciplinaridade fosse igual, quaisquer que fossem os contextos, sem nenhum tipo de respaldo ou fundamentação dos estudos anteriores, houve a necessidade de uma etapa de pesquisa de questionamento aos especialistas em nível mundial. Aos especialistas também foram apresentadas as práticas propostas em teoria e lhes foi pedido que atribuíssem notas de interdisciplinaridade às práticas sugeridas.

Para seleção dos especialistas foi feita uma busca no diretório do grupo de pesquisas do CNPq. Foram detectados: CETrans - Centro de Educação Transdisciplinar; GEPI - Grupo de Estudos e Pesquisas em Interdisciplinaridade da PUC/ SP; IEAT - Instituto de Estudos Avançados Transdisciplinares da UFMG. Um último grupo foi adicionado por conveniência em função do número de pesquisadores e seus respectivos impactos na publicação brasileira sobre o assunto, trata-se do CIRET - Centre International de Recherches et Études Transdisciplinaire na França, berço do conceito. Para operacionalizar a primeira etapa de pesquisa, o método escolhido foi o Delphi na sua forma 
política, ou seja, utilizado para buscar um consenso sobre determinado assunto (KAYO; SECURATO, I997). O método Delphi foi empregado como primeira técnica de coleta de dados por apresentar caráter exploratório e permitir que os especialistas em um determinado assunto sejam consultados simultaneamente, mais detalhes são apresentados no Quadro I.

Quadro I - Relações da construção do instrumento de pesquisa para método Delphi

\begin{tabular}{|c|c|c|c|}
\hline Temas & Autoria & $\begin{array}{l}\text { Proposições do } \\
\text { método Delphi }\end{array}$ & $\begin{array}{l}\text { Questões de pesquisa no } \\
\text { instrumento de pesquisa } \\
\text { Delphi }\end{array}$ \\
\hline $\begin{array}{l}\text { A diferença entre a } \\
\text { interdisciplinaridade } \\
\text { em geral e a } \\
\text { interdisciplinaridade } \\
\text { no ensino de } \\
\text { Administração no nível } \\
\text { de graduação }\end{array}$ & $\begin{array}{l}\text { Pombo (1994); Fazenda } \\
\text { (1999) e Lenoir (2005) }\end{array}$ & $\begin{array}{l}\text { 1)A } \\
\text { interdisciplinaridade } \\
\text { nas escolas de } \\
\text { Administração é igual } \\
\text { ao conceito puro de } \\
\text { interdisciplinaridade }\end{array}$ & $\begin{array}{l}\text { 1) Qual a definição de } \\
\text { interdisciplinaridade no } \\
\text { ensino de Administração? }\end{array}$ \\
\hline $\begin{array}{l}\text { A origem da } \\
\text { interdisciplinaridade } \\
\text { mostra que o conceito } \\
\text { possui as dimensões } \\
\text { de pesquisa, ensino } \\
\text { e projetos (extensão), } \\
\text { assim como o trabalho } \\
\text { da universidade }\end{array}$ & $\begin{array}{l}\text { Gusdorf, (1977); Piaget, } \\
\text { (1972); Japiassu (1977); } \\
\text { Bruun (2005); Klein } \\
\text { (1990); } \\
\text { Hukkinen (2012); } \\
\text { Pombo (1994); Fazenda } \\
\text { (1991, 1999); Junior et } \\
\text { al. 2009 apud Fioretin; } \\
\text { Domingues (2011) }\end{array}$ & $\begin{array}{l}\text { 2)A } \\
\text { interdisciplinaridade } \\
\text { nas escolas de } \\
\text { Administração é } \\
\text { representada pela } \\
\text { integração das } \\
\text { atividades de ensino, } \\
\text { pesquisa e extensão } \\
\text { (autores) }\end{array}$ & $\begin{array}{l}\text { 2) A integração de } \\
\text { ensino, pesquisa e } \\
\text { extensão representam a } \\
\text { interdisciplinaridade das } \\
\text { escolas de Administração? }\end{array}$ \\
\hline $\begin{array}{l}\text { A interdisciplinaridade } \\
\text { facilita o aprendizado }\end{array}$ & $\begin{array}{l}\text { Fazenda }(1991 ; 1996 ; \\
\text { 1999) }\end{array}$ & $\begin{array}{l}\text { 3)A } \\
\text { interdisciplinaridade } \\
\text { facilitaria o } \\
\text { aprendizado em } \\
\text { administração }\end{array}$ & $\begin{array}{l}\text { 3) A interdisciplinaridade } \\
\text { facilita o aprendizado em } \\
\text { administração? }\end{array}$ \\
\hline $\begin{array}{l}\text { A interdisciplinaridade } \\
\text { aperfeiçoa a tomada } \\
\text { de decisões }\end{array}$ & Fourez (1995) & $\begin{array}{l}\text { 4)A } \\
\text { interdisciplinaridade } \\
\text { aperfeiçoa a } \\
\text { competência para } \\
\text { tomar decisões } \\
\text { na formação do } \\
\text { administrador }\end{array}$ & $\begin{array}{l}\text { 4) A interdisciplinaridade } \\
\text { aperfeiçoa a competência } \\
\text { em tomar decisões do } \\
\text { administrador? }\end{array}$ \\
\hline $\begin{array}{l}\text { A interdisciplinaridade } \\
\text { desenvolve o } \\
\text { raciocínio sistêmico } \\
\text { e contribui para } \\
\text { análise de problemas } \\
\text { complexos }\end{array}$ & $\begin{array}{l}\text { Piaget (1972) e Morin } \\
(2000 ; 2007)\end{array}$ & $\begin{array}{l}\text { 5)A } \\
\text { interdisciplinaridade } \\
\text { dá suporte aos } \\
\text { administradores para } \\
\text { lidar com problemas } \\
\text { complexos }\end{array}$ & $\begin{array}{l}\text { 5) A interdisciplinaridade } \\
\text { ajuda o administrador } \\
\text { a lidar com problemas } \\
\text { complexos? }\end{array}$ \\
\hline
\end{tabular}




\begin{tabular}{|c|c|c|c|}
\hline Temas & Autoria & $\begin{array}{l}\text { Proposições do } \\
\text { método Delphi }\end{array}$ & $\begin{array}{l}\text { Questões de pesquisa no } \\
\text { instrumento de pesquisa } \\
\text { Delphi }\end{array}$ \\
\hline \multirow[t]{3}{*}{$\begin{array}{l}\text { A interdisciplinaridade } \\
\text { possui um escopo em } \\
\text { suas atividades, que } \\
\text { vai do estreito ao largo } \\
\text { e está relacionado } \\
\text { com a abrangência de } \\
\text { conhecimentos das } \\
\text { práticas adotadas }\end{array}$} & \multirow[t]{3}{*}{$\begin{array}{l}\text { Rossini e Porter (1979) e } \\
\text { Huutoniemi et al. (2010) }\end{array}$} & $\begin{array}{l}\text { 6) O número de } \\
\text { disciplinas abrangidas } \\
\text { em projetos de } \\
\text { interdisciplinaridade } \\
\text { revela o grau de } \\
\text { interdisciplinaridade } \\
\text { das escolas de } \\
\text { Administração }\end{array}$ & $\begin{array}{l}\text { 6) O número de disciplinas } \\
\text { abrangidas em projetos } \\
\text { de interdisciplinaridade } \\
\text { revela o grau de } \\
\text { interdisciplinaridade das } \\
\text { escolas de Administração? }\end{array}$ \\
\hline & & $\begin{array}{l}\text { 7) A duração de } \\
\text { tempo de projetos de } \\
\text { interdisciplinaridade } \\
\text { revela o grau de } \\
\text { interdisciplinaridade } \\
\text { de escolas de } \\
\text { Administração }\end{array}$ & $\begin{array}{l}\text { 7) A duração de } \\
\text { tempo de projetos de } \\
\text { interdisciplinaridade } \\
\text { revela o grau de } \\
\text { interdisciplinaridade das } \\
\text { escolas de Administração? }\end{array}$ \\
\hline & & $\begin{array}{l}\text { 8) A diversidade } \\
\text { de conhecimento } \\
\text { de projetos } \\
\text { interdisciplinares } \\
\text { revela o grau de } \\
\text { interdisciplinaridade } \\
\text { das escolas de } \\
\text { Administração }\end{array}$ & $\begin{array}{l}\text { 8) A diversidade de } \\
\text { conhecimento de projetos } \\
\text { de interdisciplinaridade } \\
\text { revela o grau de } \\
\text { interdisciplinaridade das } \\
\text { escolas de Administração? }\end{array}$ \\
\hline
\end{tabular}

Complementando a primeira fase da pesquisa, duas entrevistas foram realizadas com coordenadores de cursos de graduação em administração. Essa fase da pesquisa consistiu de inquietações a respeito das influências do contexto em uma escola de Administração, no nível de graduação, para iniciativas de interdisciplinaridade. Desta forma, entendeu-se que era preciso descrever quais eram as dificuldades para se desenvolver iniciativas de interdisciplinaridade em escolas de Administração no Brasil. Para isso, o método adequado seria aquele que pudesse dar profundidade aos dados, permitindo detalhamento dos conceitos, para isso foi escolhida a entrevista exploratória.

Para Richardson (2008), a entrevista é uma técnica importante que permite desenvolvimento de uma estreita relação entre as pessoas. É um modo de comunicação no qual determinada informação é transmitida de uma pessoa A para uma pessoa B. Em vez de responder à pergunta por meio de 
diversas alternativas pré-formuladas, visa a obter do respondente o que ele considera mais relevante em determinado problema. Há uma conversação guiada em que se pretende obter informações detalhadas que possam ser utilizadas numa análise qualitativa. A entrevista não estruturada procura saber como e porque algo ocorre em lugar de determinar a frequência de certas ocorrências nas quais o pesquisador acredita.

Uma vez feita a entrevista, esta deve ser transcrita e analisada (RICHARDSON, 1985). As entrevistas foram realizadas pessoalmente em dezembro de $2012 \mathrm{e}$ tiveram duração média de 50 minutos cada, foram gravadas e posteriormente transcritas. Os coordenadores de cursos de graduação em Administração estavam no cargo havia no mínimo quatro anos e se disponibilizaram a compartilhar as informações de seu curso para a pesquisa de forma anônima. Por isso não serão reveladas as escolas nas quais os entrevistados trabalham nem tampouco seus dados pessoais. O entrevistado I coordena o curso dentro de uma universidade privada em Ribeirão Preto, São Paulo; o entrevistado 2 coordena o curso dentro de uma universidade pública paulista no interior do estado. O Quadro 2 apresenta o roteiro de entrevista aplicado aos entrevistados.

Quadro 2 - Perguntas do roteiro de entrevista

O que é interdisciplinaridade na graduação em Administração?

A interdisciplinaridade melhora o aprendizado no curso de Administração?

Você considera seu curso interdisciplinar? Por quê?

Liste práticas de interdisciplinaridade do seu curso e descreva práticas que considera como exemplos de interdisciplinaridade em outros cursos.

Quais as dificuldades para tornar o curso mais interdisciplinar?

Qual a influência da avaliação do mec (Enade) das den (Diretrizes Curriculares Nacionais) nas atividades relacionadas à interdisciplinaridade? 
REFERENCIAL TEÓRICO

\section{GÊNESE DA INTERDISCIPLINARIDADE}

Interdisciplinaridade pode ser definida como a integração dos conhecimentos entre indivíduos. Este é um passo além da multidisciplinaridade e pluridisciplinaridade, e estende-se até o limite de criação de novos tipos de conhecimento e, portanto, até a transdisciplinaridade (РОмво, 1994; FAZENDA, I999; LENOIR, 2005).

Nesta perspectiva, a interdisciplinaridade em cursos de graduação funde conhecimentos entre as diferentes disciplinas. Alguns autores dizem que a interdisciplinaridade melhora a capacidade do pensamento sistêmico, fazendo com que o raciocínio e análise de problemas complexos e ambíguos se torne mais fácil (PIAGET, I972; MORIN, 2007).

Além disso, a interdisciplinaridade também ajuda na formação de habilidades de tomada de decisão (Fourez, 1995). De acordo com Fazenda (I99I) é importante para a interdisciplinaridade o processo de aprendizagem e não seu resultado, podendo ser aplicada a qualquer nível de ensino, como sendo uma atitude ou postura "interdisciplinar".

O Quadro 3 sintetiza as relações entre as origens teóricas da interdisciplinaridade nas abordagens mundiais, apresentando a relação entre as três dimensões da interdisciplinaridade: acadêmico, projeto e didática. Abordagem brasileira lida com a interdisciplinaridade como um fenômeno aplicado à didática. A Escola Nórdica (HuUtoniemi et al., 20Io) e abordagem anglo-saxônica são entendidas como mais práticas, tratando a interdisciplinaridade como projetos pedagógicos, em que a aprendizagem deve surgir com base em problemas sociais e locais, com os alunos sendo submetidos a diferentes conhecimentos, buscando soluções para os seus problemas com a realidade. Por fim, a dimensão da investigação, abordagem francesa, é que a interdisciplinaridade deve buscar novos conhecimentos e também novos temas para o avanço epistemológico, deve ser um caminho para o alcance da transdisciplinaridade. 
Quadro 3 Teorias da interdisciplinaridade: época, foco e características

\begin{tabular}{|c|c|c|c|c|}
\hline Anos & $\begin{array}{l}\text { Escola } \\
\text { Francesa }\end{array}$ & $\begin{array}{l}\text { Escola } \\
\text { Nórdica }\end{array}$ & $\begin{array}{l}\text { Escola } \\
\text { Anglo-Saxônica }\end{array}$ & $\begin{array}{l}\text { Escola } \\
\text { Brasileira }\end{array}$ \\
\hline $70-90$ & \multicolumn{4}{|c|}{ Perspectiva filosófica e epistemológica } \\
\hline $90-2000$ & \multicolumn{3}{|c|}{ Perspectiva instrumental } & $\begin{array}{l}\text { Perspectiva } \\
\text { fenomenológica }\end{array}$ \\
\hline $\begin{array}{l}\text { Tema de } \\
\text { Pesquisa }\end{array}$ & $\begin{array}{l}\text { Síntese co } \\
\text { disciplinas }\end{array}$ & $\begin{array}{l}\text { nierarquia de } \\
\text { isciplinas }\end{array}$ & $\begin{array}{l}\text { Respostas aos } \\
\text { problemas da } \\
\text { sociedade }\end{array}$ & $\begin{array}{l}\text { Novos métodos de } \\
\text { ensino }\end{array}$ \\
\hline Características & $\begin{array}{l}\text { Tentativa c } \\
\text { científico }\end{array}$ & ão do conhecimento & $\begin{array}{l}\text { Busca pela } \\
\text { operacionalização }\end{array}$ & $\begin{array}{l}\text { Relações entre } \\
\text { pesquisa e ensino }\end{array}$ \\
\hline Foco & Acadêmicc & & Projetos & Didática \\
\hline
\end{tabular}

Fonte: Adaptado de Rossini e Porter (1979); Huutoniemi et al. (2010); Fazenda (1991); Fourez (1995) e Morin (2007).

\section{ESCOPO DA INTERDISCIPLINARIDADE}

Para Huutoniemi et al. (2010) uma possível forma de definir a interdisciplinaridade diz respeito a seu escopo. Esta noção refere-se às distâncias conceituais e culturais entre as participações de diferentes conhecimentos. Sabe-se que projetos são genuínos de uma ciência-mãe e são concebidos dentro da estrutura epistemológica e metodológica de um saber homogêneo. Por sua vez, projetos interdisciplinares variam em termos de escopo. Para Rossini e Porter (1979), esta variação é chamada de "extensão" ou "alcance". Esses autores também classificam o escopo como número de participantes, pesquisadores ou professores envolvidos em um projeto.

Já para Kelly (1996), o escopo da interdisciplinaridade pode ser classificado como "abrangente" ou "estrito". Segundo no escopo estrito as áreas ou campos participantes de um projeto, seja de ensino, seja de pesquisa, são conceitualmente próximos uns dos outros, tipicamente representando o mesmo domínio de trabalho acadêmico, a mesma ciência aplicada. O escopo estrito não é simplesmente a abrangência que o projeto interdisciplinar assume, mas a familiaridade com a cultura e os conceitos de outra área. A extensão em que este projeto consegue ampliar horizontes e entrar no terreno das novas ciências é considerada a amplitude. Ainda que existam 
muitas classificações nas ciências, estes domínios podem ser as ciências naturais, os campos da engenharia, biológicas e ciências da vida, ciências sociais e humanidades (KELLY, I996).

Entretanto, segundo Sandstrom (2005) mesmo diante de um mesmo campo de domínio podem existir vácuos ou sobreposições de conceitos e culturas. Isso significa que um projeto que apresenta um escopo mais abrangente nem sempre é mais interdisciplinar que um projeto com escopo estrito. Algumas vezes ele pode nem ser interdisciplinar. Assim, os autores atentam para o uso isolado dessa variável para do escopo da interdisciplinaridade em diversos meios, conforme apresentado no Quadro 4.

Quadro 4 Escopo da interdisciplinaridade

\begin{tabular}{|llll|}
\hline Escopo & $\begin{array}{l}\text { Rossini e Porter (1979) e Kelly } \\
\text { (1996) }\end{array}$ & Huutoniemi et al. (2010) & Autoria \\
$\begin{array}{l}\text { Número de participantes, } \\
\text { pesquisadores ou professores } \\
\text { Extensão; alcance; abrangência }\end{array}$ & $\begin{array}{l}\text { Abrangente; estrito } \\
\text { Distâncias conceituais e } \\
\text { culturais }\end{array}$ & Categorias \\
\hline
\end{tabular}

Fonte: Rossini e Porter (1979); Kelly (1996) e Huutoniemi et al. (2010).

Desta forma, entende-se que enquanto a transdisciplinaridade atua na criação de novos conhecimentos, novas disciplinas com base na confluência de conteúdos cabe à interdisciplinaridade operacionalizar espaços e projetos para que os alunos relacionem os conteúdos. Sendo esta última, por sua praticidade e importância para a formação e matriz curricular dos cursos de administração, foco deste artigo. 


\section{RESULTADOS}

Os resultados da primeira rodada da técnica Delphi revelam as respostas dadas à primeira questão: "Em sua opinião qual a definição de interdisciplinaridade nas escolas de Administração?” As quinze respostas recebidas são apresentadas no Quadro 5.

\section{Quadro 5 Respostas dos Especialistas à Questão i pelo formulário Delphi}

\begin{tabular}{|c|c|}
\hline Especialista 1 & $\begin{array}{l}\text { Para mim, isso significa integrar o conhecimento além das disciplinas para } \\
\text { alcançar habilidades de gestão. }\end{array}$ \\
\hline Especialista 2 & $\begin{array}{l}\text { Significa o processo de integrar o conhecimento de diferentes disciplinas para } \\
\text { o exercício do pensamento complexo. }\end{array}$ \\
\hline Especialista 3 & $\begin{array}{l}\text { Conexão e comunicação entre disciplinas para educação de estudantes de } \\
\text { negócios. O uso de métodos e técnicas de uma disciplina para outra. }\end{array}$ \\
\hline Especialista 4 & $\begin{array}{l}\text { Um comprometimento a estudar negócios que advém de muitas disciplinas e } \\
\text { seus respectivos pontos de vista tomando como pressuposto que os negócios } \\
\text { são por si, um fenômeno interdisciplinar. Simplesmente obter projetos de } \\
\text { interdisciplinaridade em escolas de negócios não é suficiente para capturar o } \\
\text { senso de negócio como interdisciplinaridade. }\end{array}$ \\
\hline Especialista 5 & $\begin{array}{l}\text { Interdisciplinaridade, onde há disciplinas (em que o assunto é mais } \\
\text { importante), é necessária. }\end{array}$ \\
\hline Especialista 6 & $\begin{array}{l}\text { A necessidade de entender novas formas de aprender e ensinar administração, } \\
\text { preparando os estudantes para organizações sistêmicas e processos } \\
\text { interdependentes. }\end{array}$ \\
\hline Especialista 7 & $\begin{array}{l}\text { Uma mudança no entendimento em direção aos novos desafios } \\
\text { organizacionais por meio da interdisciplinaridade. }\end{array}$ \\
\hline Especialista 8 & $\begin{array}{l}\text { Construir pontes entre a teoria e a prática pelos diálogos entre academia, } \\
\text { negócios, governo e sociedade. Promover a reflexão do que é administrar, } \\
\text { qual seu propósito e mais que tudo qual o papel dos gerentes e como } \\
\text { administrar a si mesmo. }\end{array}$ \\
\hline Especialista 9 & $\begin{array}{l}\text { Na pesquisa que realizei para a minha tese de doutorado, } \\
\text { interdisciplinaridade é interação prolongada e coordenada entre duas ou } \\
\text { mais disciplinas acadêmicas próximas ou distantes, para a resolução de } \\
\text { determinados problemas complexos que não podem ser resolvidos por } \\
\text { abordagens disciplinares. E, no campo da educação, a interdisciplinaridade } \\
\text { está diretamente relacionada com as correntes pedagógicas que colocam o } \\
\text { aluno e não as disciplinas no centro do projeto pedagógico. }\end{array}$ \\
\hline Especialista 10 & $\begin{array}{l}\text { Interdisciplinaridade nas escolas de negócios significa inovação e um melhor } \\
\text { entendimento do mundo de negócios. }\end{array}$ \\
\hline Especialista 11 & $\begin{array}{l}\text { Transferir métodos e informações de diferentes disciplinas próprias do } \\
\text { currículo, com uma equipe preparada com métodos específicos de trabalho. }\end{array}$ \\
\hline Especialista 12 & Um passo para pesquisa efetiva: transdisciplinaridade. \\
\hline
\end{tabular}




\begin{tabular}{|ll}
\hline Especialista 13 & Cultura, inteligência e sensibilidade. \\
\hline Especialista 14 & Entender a complexidade do mundo. \\
\hline Especialista 15 & Necessidade de inter e transdisciplinaridade.
\end{tabular}

Nota-se que as definições são consensuais na afirmação de que não existem diferenças significativas entre o conceito puro, básico de interdisciplinaridade e o conceito de interdisciplinaridade no ensino em administração. Desta forma foi possível defini-la como "inovação pedagógica com foco no aluno, para integração coordenada de disciplinas, a fim de se entender os desafios sistêmicos dos negócios e abrir caminhos para a transdisciplinaridade”. Também é possível notar que os especialistas possuem uma visão ao encontro da escola francesa e sua identificação com a interdisciplinaridade como um construto teórico que inter-relaciona os conteúdos da disciplina transversalmente.

A segunda questão diz respeito à interdisciplinaridade e a sua relação com o ensino, pesquisa e extensão. A pergunta foi formulada como "As escolas de Administração apresentam interdisciplinaridade se suas atividades de pesquisa, ensino e extensão forem integradas?”

Tabela I Respostas dos Especialistas pelo Método Delphi

\begin{tabular}{|c|c|c|c|c|c|}
\hline Afirmações da escala Likert & $\begin{array}{l}\text { Descordo } \\
\text { Totalmente }\end{array}$ & Descordo & $\begin{array}{l}\text { Sou } \\
\text { neutro }\end{array}$ & Concordo & $\begin{array}{l}\text { Concordo } \\
\text { Totalmente }\end{array}$ \\
\hline $\begin{array}{l}\text { Interdisciplinaridade no ensino de } \\
\text { Administração é igual ao conceito puro } \\
\text { de interdisciplinaridade }\end{array}$ & 0 & 0 & 5 & 7 & 1 \\
\hline $\begin{array}{l}\text { Interdisciplinaridade pode facilitar o } \\
\text { aprendizado na educação gerencial } \\
\text { (ensino em administração). }\end{array}$ & 0 & 0 & 1 & 10 & 4 \\
\hline $\begin{array}{l}\text { Interdisciplinaridade melhora a } \\
\text { competência de tomar decisões }\end{array}$ & 0 & 0 & 1 & 10 & 4 \\
\hline $\begin{array}{l}\text { Interdisciplinaridade desenvolve } \\
\text { pensamento sistêmico e apoia a análise } \\
\text { de problemas complexos. }\end{array}$ & 0 & 0 & 0 & 6 & 9 \\
\hline $\begin{array}{l}\text { O número de projetos de } \\
\text { interdisciplinaridade revela o grau de } \\
\text { interdisciplinaridade em um curso de } \\
\text { Administração. }\end{array}$ & 0 & 4 & 5 & 5 & 1 \\
\hline
\end{tabular}




\begin{tabular}{|c|c|c|c|c|c|}
\hline Afirmaçōes da escala Likert & $\begin{array}{l}\text { Descordo } \\
\text { Totalmente }\end{array}$ & Descordo & $\begin{array}{l}\text { Sou } \\
\text { neutro }\end{array}$ & Concordo & $\begin{array}{l}\text { Concordo } \\
\text { Totalmente }\end{array}$ \\
\hline $\begin{array}{l}\text { A duração dos projetos de } \\
\text { interdisciplinaridade revela o grau de } \\
\text { interdisciplinaridade em um curso de } \\
\text { Administração. }\end{array}$ & 0 & 3 & 9 & 2 & 1 \\
\hline $\begin{array}{l}\text { Diversidade de conhecimentos } \\
\text { abordados em projetos de } \\
\text { interdisciplinaridade revela o grau de } \\
\text { interdisciplinaridade em um curso de } \\
\text { Administração. }\end{array}$ & 0 & 1 & 3 & 9 & 2 \\
\hline
\end{tabular}

Há tendência de concordância às afirmações, porém só há uma resposta que concorda fortemente. Trata-se da afirmativa sobre o desenvolvimento da interdisciplinaridade e o raciocínio sistêmico, o que vem ao encontro dos clássicos Piaget (1972) e Morin (2000; 2007). A diferença entre as respostas neutras e de concordância também se apresentaram insignificantes. Ficou claro que, na opinião dos especialistas, a interdisciplinaridade abrange mais que apenas ensino, englobando as atividades de pesquisa e extensão e se associando ao foco teórico já definido pelos trabalhos da escola nórdica. Essa afirmação amplia a abrangência de trabalho dentro do curso de Administração. $\mathrm{Na}$ medida em que se considera que, para haver interdisciplinaridade é preciso relacionar ensino, pesquisa e extensão, também é salutar afirmar que, para que haja interdisciplinaridade, não basta apenas que um curso inter-relacione conteúdos de disciplinas, mas que relacione a pesquisa que o corpo docente realiza com os problemas econômico-sociais que o entorno do curso também apresenta.

A terceira questão diz respeito à possibilidade de a interdisciplinaridade ser benéfica à formação em Administração. Essa questão apenas confirma a percepção das vantagens da interdisciplinaridade, tendo em vista que, se os especialistas realizam estudos sobre a interdisciplinaridade e trabalham com ela, é porque acreditam no potencial de sua utilização. O que motivou esse item foi uma busca por saber se essa mesma percepção se confirmava no ensino, conforme propõe Fazenda (1991; 2006).

Foi possível estabelecer um consenso entre os especialistas. Quase todos concordam ou concordam totalmente que a interdisciplinaridade melhora 
a formação em Administração. Somente um deles se mantém neutro em relação à afirmação.

A quarta questão era relacionada à interdisciplinaridade e à competência para tomar decisões. Fourez (I995) propõe que a interdisciplinaridade amplia a capacidade analítica e de realização de conexões entre as ideias, o que abriria o pensamento a novas percepções e observações da realidade. Consequentemente, qualquer profissional pode adquirir habilidade para tomar decisões. Neste caso, também é possível perceber o consenso entre os especialistas, considerando que a interdisciplinaridade melhora a competência para a tomada de decisão na formação do administrador.

A questão que aborda o suporte que a interdisciplinaridade pode fornecer aos administradores para lidar com problemas complexos teve respostas dos especialistas aparentemente consensuais. Seis deles concordam e nove concordam totalmente com a afirmação. Essa resposta corrobora com Gusdorf (1977), mostrando que os especialistas concordam que, quando aplicada ao contexto de formação em Administração, a interdisciplinaridade pode capacitar os alunos para lidarem melhor com problemas complexos.

No que tange ao escopo da interdisciplinaridade. Segundo Rossini e Porter (1979) e Huutoniemi et al. (20I0), este varia do largo ao estreito, podendo ser identificado pela abrangência de conhecimentos que uma atividade ou projeto de interdisciplinaridade pode alcançar. As Questões 6 a 8 pormenorizaram por meio da diversidade de conhecimentos em número de disciplinas, duração da atividade e diversidade de conhecimento.

Na sexta questão os resultados foram ambíguos. Há uma leve concordância com a afirmação sobre o número de disciplinas abrangidas nos projetos interdisciplinares e sua relação com a interdisciplinaridade da escola de Administração. Os resultados mostram-se dispersos, com número parecido de respostas concordando, discordando e mantendo-se neutras frente à abordagem do número de disciplinas.

O que se mostrou sem significância na percepção dos especialistas foi o tempo de duração dos projetos interdisciplinares. Os especialistas se mostraram neutros a essa relação, conforme se pode observar na Tabela i. Há uma concentração de respostas indicando que o tempo de duração não revela o 
grau de interdisciplinaridade de uma escola de Administração. Os especialistas não formam um consenso sobre se o fato de um projeto existir há muito tempo corresponde a uma ampliação de seu grau de interdisciplinaridade.

Como última questão as respostas indicam que os especialistas concordam que a diversidade de conhecimentos abordada em projetos interdisciplinares revela o grau de interdisciplinaridade nas escolas de Administração.

Desta forma, foi considerado que o escopo da interdisciplinaridade na formação em Administração pode se constituir pela diversidade de conhecimentos que estão sendo abordados em um projeto ou atividade interdisciplinar.

No espaço reservado às observações, dois especialistas elogiaram o trabalho, dizendo ser muito importante, em virtude do momento pelo qual as escolas estão passando. Um especialista mostrou-se receoso a respeito de onde e como as informações seriam divulgadas. Neste caso, foi-lhe enviado um correio eletrônico com todas as informações sobre como os dados seriam expostos, comunicando-lhe ainda que o trabalho estivesse disponível no portal de teses da usp, porém infelizmente a versão completa seria disponibilizada somente em português.

Um comentário feito no formulário merece destaque: "a interdisciplinaridade faz a escola mais competitiva devido aos problemas ambientais das organizações, o aluno de graduação vai responder mais eficientemente às demandas da empresa, sem dúvida sobre isso". Essa reflexão vem ao encontro das afirmações sobre as exigências severas que o ambiente competitivo vem fazendo às escolas de Administração e a hesitação que elas parecem manifestar diante do problema (ZELL, 200I; CORNUEL, 2005).

Enfim, foi possível entender que os especialistas têm um consenso sobre a definição de interdisciplinaridade no ensino de Administração. Há convergência para uma ação programada dos agentes de ensinoaprendizagem, para a modificação do estado das coisas nas escolas de Administração.

Sobre os resultados das entrevistas, os dois coordenadores aceitaram o convite de prontidão e se mostraram entusiasmados com a participação na pesquisa. 
Na primeira questão da entrevista, "I) O que é interdisciplinaridade na graduação em administração?”, o primeiro entrevistado mostrou-se taxativo ao dizer que "é quando você tem uma matriz curricular com as disciplinas e suas respectivas ementas e consegue trabalhar uma relação e uma correlação entre essas disciplinas, criando situações e contextos em que pode utilizar os conceitos aprendidos nestas disciplinas”. Já o segundo entrevistado apontou certa nebulosidade do conceito. Em sua visão, "O problema da interdisciplinaridade é entender o que ela significa, é o fato de se ter no curso de Administração a interdisciplinaridade. [...] Você tem gente das humanas, das áreas técnicas da administração, da economia, das engenharias, principalmente a de produção, da contabilidade, das ciências sociais. Esse conjunto de coisas tem que formar um profissional que não é de nenhuma dessas especialidades, e sim de outra especialidade, que é gerir a empresa. Então, aí você já tem a dificuldade de entender o que é interdisciplinaridade. Para mim este é um dos grandes nós do curso de Administração".

Percebe-se que os entrevistados possuem visões diferentes sobre o que é a interdisciplinaridade. O primeiro a percebe na relação das disciplinas, como algo a ser desenvolvido no curso; para o segundo ela é falta de coerência e coesão dos conteúdos e da origem do corpo docente, algo que aumenta a complexidade e desafia a integração do curso na convergência da formação de um profissional, convergindo com o conceito dos especialistas. Destacase que, mesmo retomando certo viés do significado do termo, o segundo entrevistado aponta a nebulosidade que paira no curso de Administração, em função da não definição de um objetivo claro de formação. Ambos salientam, mesmo sem ter havido um questionamento sobre esse ponto, a necessidade como diz o primeiro entrevistado - "da atuação" ou da "extraclasse", ou seja, de a interdisciplinaridade se apresentar como algo para além das disciplinas. O segundo entrevistado aproxima o conceito à multidisciplinaridade, algo que revela alguma dúvida na definição do conceito.

Na segunda questão, "2) A interdisciplinaridade melhora o aprendizado no curso de Administração?”, o primeiro entrevistado afirma que sim, porém salienta a necessidade de que a aplicação da interdisciplinaridade 
seja planejada, medida ou ao menos controlada. "Por exemplo, vou pegar minha disciplina: Marketing e Custos. Quando você vai desenvolver um produto, por exemplo, tem de ter noção da estrutura de custos. Então eu tenho partes conceituais da estrutura de custos e partes conceituais da estrutura de marketing. Posso ver isso separado ou conjuntamente... A partir do momento em que você cria contextos, em que cria situações, o aluno, no caso o futuro gestor, tem de realmente desenvolver, tem de buscar por ele mesmo a questão do aproveitamento destes conteúdos de uma forma, uma vivência prática, diante de um problema a ser solucionado. Os docentes dão os caminhos, checam o que foi realizado. Acho que você dá um passo rumo ao aprendizado ao não simplesmente replicar ou, o que daria para fazer isoladamente, juntar. Eu não vejo proveito nisso...Quando deixa de ser custos e marketing, é a solução de um problema que transpõe as disciplinas isoladas, e aí você começa ter um aproveitamento." Nota-se a preocupação deste coordenador com a criação de contextos, ou seja, a necessidade de se aliar conteúdos teóricos e explícitos com as necessidades das empresas, permitindo que o aluno desenvolva suas próprias conexões. Já o segundo entrevistado concorda com a afirmação de maneira indireta. Para ele, o curso de Administração sofre com dois problemas para criar interdisciplinaridade: a natureza do curso e a estrutura departamental da sua universidade. Ele aponta os problemas das disciplinas ministradas por docentes de outras áreas e o impacto da diferença de visão do universo empresarial na qualidade do curso. Em um dos trechos, ele aponta: "Por exemplo, estatística, o,00006 de algo pode fazer muito sentido em física e química, mas em administração pode não fazer. Aqui eu posso trabalhar com arredondamentos, são universos diferentes". Ele ainda salienta a desinformação dos docentes em relação aos objetivos do curso, mostrando que é preciso primeiramente vencer essa primeira barreira, para depois se pensar em estratégias de interdisciplinaridade: "É a cultura de conteúdos que acabam não se relacionando, fragmentados, desvinculados do objetivo do curso. Eu me lembro de que, em minha tese, a primeira pergunta que eu fazia ao docente era: 'Você conhece o projeto pedagógico do curso? Ele nunca o havia lido. Se eu não sei qual a formação, qual o perfil do aluno, 
qual o objetivo do curso, e entramos nele só a partir de uma disciplina, não conheço o projeto? Eu acho que tem uma dificuldade". Neste relato, o entrevistado 2 salienta informações importantes também destacadas pela teoria. Para Demo (200I), as áreas das ciências comunicam-se pouco e resistem muitas vezes a comunicar-se. Mesmo dentro do espaço comum da comunicação ela é frequentemente pequena ou inexistente. Em nome da autonomia, criam-se feudos que, como todos sabem, só prejudica a inovação. O entrevistado 2 também concorda que a interdisciplinaridade acaba sendo "mais uma tarefa" a ser realizada, como destacam Parker e Guthrie (20I0) e Ferreira (199I). O entrevistado I enfatiza que a geração atual tem necessidade de compartilhar coisas, de fazer trocas constantes de informação, e as empresas estão cada vez mais demandando profissionais multitarefas. Ele afirma que isso não é ensinado e nem ao menos falado em sala de aula. Para ele, tudo o que se puder fazer para uma aproximação melhor, uma linguagem melhor - não no sentido da formação técnica, mas da compreensão da questão do direcionamento mais lógico para compreensão de situações - contribuirá para uma tomada de decisão mais adequada. E continua: "E isso tem a ver com esta questão de trabalhar a interdisciplinaridade etc. Eu acho importante, apesar de bastante difícil de ser colocado em prática”. Fica exposto aqui o problema da falta de inovações pedagógicas no ensino em Administração, o que foi tratado no estrangeiro por Bennis e O’Toole (2005) e Hambrick (1993) e no âmbito nacional por Dias (1991) e Nicolini (2003).

A terceira questão dizia respeito à visão acerca da interdisciplinaridade no próprio curso do coordenador: "3) Considera seu curso interdisciplinar? Por quê?”. Ambos apontaram que não, mas que a interdisciplinaridade está presente em alguns momentos. Ambos salientam a importância de se aperfeiçoar o curso neste aspecto: "Eu acho que ele tem momentos assim, mas as disciplinas ainda são extremamente pontuais, isoladas. Não chamaria o curso de interdisciplinar, não". Já o segundo entrevistado afirma que o curso apresenta uma "interdisciplinaridade fragmentada". Enfatiza esse ponto dizendo que a estrutura pública ainda contribui negativamente para isso: "Uma boa faculdade particular não tem a burocracia da universidade 
pública. A burocracia impeditiva. Neste ponto, todo mundo fala a mesma língua. Uma pessoa que foi contratada se senta e conversa sobre o que se espera dele. Na universidade pública, essa conversa não acontece. O cara vai entrar em sala de aula e trabalhar o projeto de pesquisa que ele tem naquele momento. Tangencia o conteúdo em função da área de pesquisa que ele tem naquele momento. Acho que a universidade pública terá que se repensar em relação a este modelo departamental que ela tem hoje. A dedicação exclusiva enfatiza isso. Além do mais, o docente é cobrado por produtividade em pesquisa, o ensino em graduação não conta." Para o segundo entrevistado, muitas coisas poderão se alterar com o regime de cotas a ser implantado no estado de São Paulo, no qual, gradativamente, 50\% das vagas serão destinadas a alunos que cursaram os ensinos fundamental e médio na escola pública: "O aluno de hoje pode até 'gazetear' um pouco em sala de aula. Se ele estudar bastante antes da prova, vai passar. É um aluno bem formado, tem uma condição socioeconômica diferenciada. É um aluno que chega pronto... Nós vamos ter alunos que, na média, tiveram ensino fundamental e médio ruim. São alunos acostumados a absorver informação na base da 'decoreba'. Na hora que este aluno encontrar o professor que só sabe ensinar, vai haver problemas." Fica evidente que a melhoria de qualidade do ensino de Administração direcionará as estratégias de ensino para a interdisciplinaridade. "A aula expositiva funciona, óbvio, mas eu não posso ter um curso em cima de aula expositiva. O que está muito bom hoje vai tender a ficar muito frágil. Outro dia eu estava vendo o plano de aula de alguns docentes. É um tema por aula até o dia da prova. Dentro da própria disciplina tem uma fragmentação muito evidente. Informação, só informação nova. A pergunta é 'Em que momento essa informação é trabalhada em cima de uma situação-problema?'. O aluno pensa: 'Por que estou aprendendo isso? No que isso vai ser útil na minha profissão?'. Mas isso é importante para qualquer formação, seja para o aluno que se forma para o mercado, seja aquele que vai se tornar um docente pesquisador." $\mathrm{O}$ entrevistado também desenvolve a ideia de que não há estímulos para que os docentes ou o coordenador do curso melhorem suas estratégias dentro de sala de aula. Assim, os alunos estudam cada vez menos, no máximo duas 
horas por semana, para todas as disciplinas, independentemente da nota do curso dada no Enade. Para ele, os docentes têm uma abordagem contrária ao que seria adequado: "O docente apresenta o texto normalmente em aula expositiva, monta as transparências em cima dos textos. $\mathrm{O}$ aluno dá uma olhada nas transparências e faz a prova. Trabalho em grupo: rachado, cada um faz um pedaço. Ou então os alunos são mais práticos ainda: 'Olha, vamos fazer o mesmo grupo e cada um faz o trabalho de uma disciplina'”. Neste ponto o coordenador mostra como a fragmentação das disciplinas e a falta de integração entre os trabalhos acadêmicos pode produzir efeitos ainda mais nocivos de acompanhamento e aprendizagem dos alunos. Estes agem de forma mecânica em relação ao conteúdo, apenas o absorvendo para ser aprovado nas disciplinas ou fazendo somente uma fatia dos trabalhos de seu grupo de colegas. Neste caso é evidente a questão do contexto ambiental das instituições públicas. As universidades públicas cobram de seus professores que realizem publicações científicas, deixando que suas aulas sejam ministradas com mais autonomia. Como os alunos que conseguem uma vaga em uma das três universidades públicas paulistas são mais bem preparados, não há desafios de raciocínio nas aulas expositivas.

A quarta questão solicitava que os coordenadores apontassem práticas interdisciplinares em seu curso ou em outro curso de que tivessem conhecimento. O primeiro entrevistado revelou que "A quarta etapa tem um trabalho, é um projeto, na verdade, um projeto desenvolvido na disciplina Planejamento de Marketing, totalmente voltado para mercado. O aluno realmente tem que desenvolver um plano de marketing, como se ele fosse uma empresa de consultoria, desenvolvendo todas as fases. Tem que ir atrás, prospectar um cliente, um cliente que ele não conhece. Não pode ser a empresa da família, de um conhecido, nada disso". Também acrescenta que a empresa tem de ser totalmente desconhecida: "Ele precisa criar essa coragem, passar o oleozinho de peroba no rosto, bater palmas na frente da empresa e dizer: 'olha, eu sou fulano de tal e vim te vender um projeto'. Aí depois ele assina um contrato com essa empresa, e o que ele tem para oferecer à empresa é fazer uma adaptação da parte teórica a uma empresa que muitas vezes não tem orçamento definido, não tem sistema de informação, 
e isso o ajuda a pensar." Ficou muito claro na fala deste coordenador que ele descrevia sua vivência como docente mais que a de coordenador de curso. Ele destacou que, ao entrar em contato com a parte estratégica de uma empresa, o aluno percebe um sistema produtivo desorganizado. Então há uma necessidade de se buscar informações dentro da disciplina de Administração da Produção, por exemplo: "Ele (o aluno) se depara com uma cultura organizacional que vai entender melhor por meio das disciplinas de Gestão de Pessoas, de outra etapa. Nesta etapa também temos a disciplina de Análise das Demonstrações Financeiras, que lhe propicia subsídio e uma série de pontos referentes à gestão de fluxo de caixa da empresa. Quer dizer, isso não está no roteiro do projeto, mas sem essas informações ele vai ter que buscar, vai se deparar com problemas, pois não recebe todas as informações na disciplina de Planejamento de Marketing. Então tem de correr atrás de conteúdos de outras disciplinas até fora desta etapa. Quer dizer, acho que essa etapa é muito produtiva. Os alunos pontuam que ela é a mais difícil em termos operacionais. O projeto, entretanto, é o que proporciona maior aprendizado para eles. Eu classificaria não somente como interdisciplinar, mas também como transdisciplinar essa etapa." Este coordenador explica que ele mesmo teve essa ideia como professor da disciplina de Marketing por ser formado em Administração e ter executado muitos trabalhos que pouco teria agregado à sua formação. Essa ideia nasceu da tentativa de se obter a visão do aluno e do hoje profissional de mercado na área de consultoria. Ele entendeu do que o mercado necessitava e o que o aluno necessitava: "Então a ideia veio disso aí, fazer uma coisa em que os alunos pudessem realmente vivenciar situações reais e serem responsáveis pelo processo decisório, prestando uma consultoria como uma empresa real".

O exemplo apontado é interessante, mas apresenta um esforço do docente da disciplina de forma isolada, não uma prática interdisciplinar comum ao curso. O segundo entrevistado tem uma visão mais contundente. Para ele, as técnicas de interdisciplinaridade dentro de sala de aula caem bem quando se tem um grupo homogêneo: "Mas eu tenho um pé atrás com técnicas, (Problem Based Learning) PBL etc. Eu as considero recursos. Você pode lançar mão delas, mas não basear nelas todo o seu curso. Acho perfeito haver 
simulação, pois ela tem o papel de forçar o aluno a juntar conteúdos para a tomada de decisão. Ele vai ter que medir as consequências daquilo. Acho que é uma das poucas coisas que a gente ainda tem em comum no curso de Administração: os jogos de empresa e simulação. Mas depende muito da ação docente. A ação docente é muito conservadora, muito tradicional. Mesmo na disciplina Didática do Ensino Superior o que se ensina são técnicas de I808”. O coordenador também critica as técnicas utilizadas nos cursos de Didática do Ensino Superior na pós-graduação strictu senso da Administração, que pouco têm a ver com o ensino de Administração, mostrando as dificuldades de aprender a fazer interdisciplinaridade neste curso pelo professor. Em vez disso transmitem em técnicas ultrapassadas como o microensino. Outro ponto destacado por ele é a questão do ensino por estudo de caso. "Wharton, Harvard estão revendo, estão colocando algumas questões que são fundamentais, de ética. Eu não tenho nada contra os estudos de caso, mas não acho que eles devam ser o modelo do curso. Acho que construir um curso como Harvard estava fazendo virou um modelo de cursos, sem muita reflexão”. As respostas parecem mostrar insatisfação pelo uso excessivo da aula expositiva como método de ensino, mas também chamam a atenção para outros extremos, como utilizar outra técnica integralmente durante o curso. Para os coordenadores, é preciso renovar as técnicas de ensino e abordar o conteúdo de forma contrária, partindo do problema da empresa para a exposição dos conteúdos.

A quinta pergunta pedia que os coordenadores apontassem as principais dificuldades para se tornar o curso mais interdisciplinar. Ambos apontam que é a incapacidade da coordenação de ter instrumentos de gestão da equipe de docentes. Na fala do entrevistado I, "a questão da própria postura docente de criação de desafios para os alunos"; e para o entrevistado 2, "Olho, vejo e fica tudo bem. Os docentes se acomodam por várias razões. Dá muito trabalho desenvolver situações-problema. Não remunerado e não recompensado. Eu tenho que pensar situações, eu tenho que pesquisar os problemas atuais das empresas. Uma série de situações que não se pagam em uma hora/aula de graduação. Quando se trabalha com ensino voltado para o aluno, se passa um dia montando uma aula ou uma avaliação. Em uma prova de quatro questões, 
você tem que montar a prova. Há uma expectativa de resposta. $\mathrm{O}$ aluno termina a prova, eu entrego um gabarito com a expectativa de resposta para ele. Os docentes não gostam de trabalhar mais em sala de aula. O professor deve expor a matéria e fazer seu trabalho, porque este é o modelo que eles aprenderam desde que entraram no ensino fundamental até a começarem a dar aulas. Como aluno, aprenderam que têm que absorver um conjunto de informações que vão ser cobradas na prova. É uma concepção de escola de 1808 , da época em que a família real veio para o Brasil e abriu a primeira universidade. A aula era expositiva porque os alunos não tinham acesso ao livro, e o aluno tinha que memorizar. Mas em 20I2, com internet e acesso a informação por todo lado, continuamos dando aula como era 200 anos atrás". É possível notar, nas palavras do entrevistado 2, que ele analisa a questão do distanciamento do ensino e da prática das escolas de Administração, bem como também opina a respeito da falta de inovações e do engessamento que o curso apresenta diante da atualidade das empresas. O entrevistado i também aponta na mesma direção, mas salienta a questão do trabalho em equipe e do comprometimento dos professores: "O que eu acho mais difícil ainda hoje, para que você consiga executar um bom projeto interdisciplinar, é o comprometimento dos docentes. Isso para mim é um fator-chave. Não estou dizendo qualificação, porque doutor hoje você contrata inclusive com alto índice de publicação. Isso tudo está disponível no mercado hoje. O que não está disponível é o comprometimento do docente. Não vou nem dizer a formação, mas o comprometimento com a educação do aluno da universidade. É o que eu vejo que faz diferença na educação." Para ele, quando se tem uma equipe comprometida com a educação, com a formação do aluno, os professores se esforçam por formar alunos críticos. Além disso, quando se é exigente, o aluno também passa a ser mais exigente com o docente. Então, desta forma o aluno mais crítico e mais exigente vai obrigar o professor a sair da zona de conforto, o que nem sempre é o que ele deseja, na visão deste coordenador, concordando novamente com Parker e Guthrie (20I0) e Ferreira (199I).

A última pergunta tratava da avaliação do MEC e as DCN, querendo saber se os coordenadores percebiam alguma relação com a interdisciplinaridade. Ambos responderam que não, mas concordaram que a avaliação tem seu 
mérito, pois é necessário que haja certo controle do MEc. Porém ainda a percebem como insuficiente para avaliar a capacidade de formação. Diz o entrevistado r: "Uma vez que são dois agentes envolvidos e apenas se dá nota para o curso, como avaliação da instituição, acho que a avaliação é bastante parcial. Sou a favor da avaliação, desde que saia no diploma do aluno o seu desempenho. Quando a nota da instituição fica na mão do aluno, ocorrem casos - que não são poucos - de alunos descomprometidos, alunos que estão com uma mágoa da instituição... Para tais alunos, realmente não importa se terão uma nota ruim, pois querem o certificado, o diploma. Então eu sou a favor da avaliação, desde que os critérios de composição da nota tenham mais transparência, porque ninguém consegue entender a forma de cálculo. Uma vez que o aluno é agente do processo, que ele também traga sua nota no diploma". O entrevistado 2 vai ainda adiante e afirma o seguinte: "Se eu não tiver um bom aluno, não adianta. Costumo brincar assim: se eu pegar uma escola com nota I no ENADE e colocar todos os alunos na USP, FGV ou qualquer escola nota 5 , essas instituições, ao final, ficarão com nota I. E se levar os alunos da usp para a escola nota I ela vai tirar 5. O desafio está aí. Como é que eu pego este aluno, com formação precária no ensino médio e fundamental, e consigo formar um bom profissional? Se você olhar sob o ponto de vista do currículo, é muito parecido na escola que tirou i e na escola que tirou 5. Estão lá os mesmos conteúdos, bem dados ou mal dados, mas o conteúdo está lá. [...] O que diferencia hoje é se o aluno que está fazendo a avaliação tem repertório e ferramentas intelectuais que lhe permitam chegar a uma conclusão por conta própria."

Em relação às DCN, os entrevistados concordam em dizer que são importantes, mas não suficientes para conduzir um curso de Administração, para se saber quais são as atividades que devem ser desenvolvidas em prol da interdisciplinaridade. Para ambos os coordenadores entrevistados, não há relação direta ou qualquer influência positiva da avaliação do MEC nem das DCN nas práticas de interdisciplinaridade desenvolvidas pelos cursos de Administração.

O que se pode afirmar, com base na análise destas entrevistas, é que os coordenadores têm um razoável conhecimento sobre o que é a 
interdisciplinaridade e consideram-na favorável ao ensino de Administração. A natureza fragmentada do curso não contribui para que as práticas se instalem naturalmente, sendo necessário realizar esforços por parte da coordenação e do corpo docente, para que elas se desenvolvam. É considerado um desafio de integração de conteúdos conseguir estabelecer práticas interdisciplinares em um curso de Administração.

Outra questão é a consciência da não interdisciplinaridade do seu curso e a descrição de diferentes barreiras, em função da estrutura pública ou privada das instituições que oferecem os cursos. Na universidade privada, a falta de comprometimento, de engajamento dos docentes com o ensino é apontada como principal causa da não interdisciplinaridade. Na universidade pública, o foco de cobrança na produtividade em pesquisa faz com que os docentes se esforcem mais nas atividades de pesquisa, ainda mais que seus alunos já se apresentam com uma formação anterior sólida, facilitando sua aprendizagem na sala de aula.

A coordenação dos cursos de Administração não pode ser representada totalmente pela visão dos dois coordenadores, porém é possível perceber que há uma fraca articulação do corpo docente por parte da coordenação, que não exerce sua responsabilidade no processo de estimular a interdisciplinaridade nos cursos. 


\section{CONSIDERAÇÕES FINAIS}

O objetivo deste trabalho foi evidenciar a visão de especialistas e coordenadores de cursos de administração sobre a interdisciplinaridade no ensino em administração. Este objetivo foi alcançado e, após a execução das etapas de pesquisas planejadas e objetivos específicos, foi possível explorar a visão desses dois grupos sobre a temática. O resultado esclareceu a lacuna teórica do conceito de interdisciplinaridade aplicado nas escolas de Administração como também, apontou possíveis "variáveis" para criar interdisciplinaridade indicando o quanto de seus esforços estão sendo direcionado para o escopo da interdisciplinaridade.

A abordagem da escola nórdica (Huutoniemi et el., 20I0) mostra que a interdisciplinaridade no ensino deve ser tratada como projeto, como se a Instituição de Ensino Superior, IEs, fosse uma empresa e um de seus resultados fosse o nível de interdisciplinaridade na graduação. Essa visão vai ao encontro do que propõe Fazenda (199I), que percebe a interdisciplinaridade como fenômeno do contexto de determinada escola que rejeita padrões rotulados como sendo interdisciplinaridade.

Em função do pensamento teórico acerca da interdisciplinaridade, é preciso concluir que não deve existir "receita de bolo" de como executar a interdisciplinaridade em determinado curso. Isso pode depender da infraestrutura, do contexto social local, da formação prévia dos docentes e do perfil comportamental dos alunos, entre outras coisas. Contudo é possível que as escolas e cursos de Administração atentem para a necessidade de tornar seus conteúdos interdisciplinares, a fim de oferecer soluções de ensino mais efetivas para satisfazer, entre outros objetivos, a necessidade de atuação do profissional de gestão no mercado.

Segundo os dados coletados pelo método Delphi não há diferença significativa da interdisciplinaridade em qualquer outro contexto. Sua importância foi reafirmada por eles, para quem, de modo geral, a interdisciplinaridade é benéfica à aprendizagem na administração, pois aperfeiçoa a competência para a tomada de decisões do administrador e desenvolve raciocínio para resolução de problemas complexos. Não foram 
aceitas as proposições de que o tempo de duração e o número de disciplinas abrangidas em projetos interdisciplinares poderiam mensurar o grau de interdisciplinaridade. Por fim, o escopo da interdisciplinaridade em escolas de Administração, no nível de graduação, limitou-se, dentro das opções de variáveis sugeridas na literatura, à diversidade de conhecimentos abordados.

Os coordenadores entrevistados apresentaram noções claras do conceito de interdisciplinaridade e acreditam em sua importância no aprendizado de administração. Ambos não consideram os próprios cursos como interdisciplinares e têm dificuldades diferentes para tornar seus cursos mais interdisciplinares. Há algum conhecimento sobre práticas de outros cursos, mas nada de caráter inspirador. Ambos veem algumas vantagens na avaliação do MEC, mas não percebem relação com a interdisciplinaridade.

As entrevistas mostraram que os coordenadores valorizam a interdisciplinaridade e consideram-na favorável ao ensino de administração. O entrevistado i considera a interdisciplinaridade como relações de conteúdos entre disciplinas. $\mathrm{O}$ entrevistado 2 considera a interdisciplinaridade um desafio ao curso, haja vista a natureza fragmentada das áreas que compõem as disciplinas do curso. Concordam ao revelar, em suas palavras, que a interdisciplinaridade nos cursos de Administração não pode ser resumida na integração de conteúdos pela grade curricular apenas, mas deve ser algo para além das disciplinas.

Ambos não consideram o curso como interdisciplinar. Por pertencerem a estruturas diferentes (universidade pública e universidade privada), apresentam dificuldades diferentes para programarem iniciativas interdisciplinares. Na universidade privada, o coordenador aponta a falta de comprometimento dos docentes com o ensino, e na universidade pública o foco dos docentes está na produtividade em pesquisa. Também salienta a influência da estrutura departamentalizada e a excessiva burocracia da gestão pública.

Quanto às práticas interdisciplinares, o entrevistado I aponta técnicas de ensino que não sejam apenas a aula expositiva, além de apontar que o ensino por projetos pode gerar resultados interdisciplinares. O entrevistado 2 também salienta a necessidade de mudança das técnicas de ensino/ 
aprendizagem para combater a falta de interdisciplinaridade, como trazer a realidade local e a problemática das organizações para dentro da sala de aula, questionando o modo como os modelos de administração são apresentados aos alunos.

Foram escassos os exemplos de interdisciplinaridade em outros cursos: apenas o ensino por projetos. Questionou-se o esgotamento do uso do método de estudo de caso e a da técnica PBL. Também considerados inócuos foram os resultados do MEC, que pretendem incentivar práticas de interdisciplinaridade por meio de suas avaliações e das DCN. O entrevistado 2 ressaltou a necessidade de avanço na interdisciplinaridade, principalmente na busca pelo desenvolvimento da atividade cognitiva sistêmica, capaz de lidar com problemas organizacionais complexos.

Diante dessas informações, é trabalho dos cursos, por meio de seu corpo docente e sua coordenação, diagnosticar com maior precisão o seu caso particular diante da média dos fatores apresentados e, a partir daí, criar estratégias específicas para enfrentar suas dificuldades. Agindo desta forma, as abordagens da interdisciplinaridade feitas pela escola nórdica e pela escola fenomenológica estarão sendo contempladas, pois a interdisciplinaridade passará a ser tratada como projeto, como resultado do processo de ensino no curso de Administração. Contudo, não deixa de ser algo fenomenológico, pois vai buscar, dentro de suas peculiaridades, soluções específicas, caso a caso, para estímulo à interdisciplinaridade.

Entretanto, não se pode propor uma mudança radical nas escolas de graduação em Administração. Afinal, “a construção do conhecimento interdisciplinar se processa por estágios ou etapas de maturação de consciência”, salienta Lück (2002, p. 65).

Não se pode afirmar que a pesquisa é a causa da interdisciplinaridade, mas estabelece-se uma nova lacuna quando a escola de Administração é criticada por não apresentar em suas pesquisas resultados relevantes para as organizações (ANTUNES; THOMAS, 2007). Syvertsen (2008) e Porras (I998), citado por Hay (2008), contribuem para esta argumentação e lembrando que o problema da pesquisa em administração não é quanto e sim como se faz. Há alta produtividade nos cursos de Administração, porém a falta 
de aplicabilidade, de implantação prática, o que acaba por minimizar seus resultados. Para Demo (200I), a escola deve reproduzir conhecimento por meio da sua construção política com os alunos.

Também é possível retomar a ideia de Zell (200I) de que a maior perda da escola de Administração foi o enfraquecimento da didática. Como visto na amostra pesquisada, não se podem fazer distinções entre IEs públicas e privadas. Há indícios, pela fala dos coordenadores nas entrevistas, de que tanto as IEs públicas como as privadas não têm o ensino como foco principal. Nas IEs públicas, os docentes centralizam seus esforços na pesquisa, enquanto que nas IEs privadas os alunos são tratados como "clientes" e o ensino passa a ser cada vez mais "spoon-fead" ou, como chamamos no Brasil, "mastigado". Essas duas percepções levam a crer que a escola de Administração não conseguiu atingir uma melhora da didática e, posteriormente, uma melhora do ensino dos futuros administradores. Porém, segundo a American Association for Higher Education and Accreditation, AAHEA (2012) não se podem apontar culpados por esta situação, haja vista que as escolas tiveram um crescimento exponencial desde a década de 1960 até os dias de hoje. Mais do que isso, seu ambiente também se alterou significativamente.

O trabalho empreendeu esforços em duas áreas de pesquisa academicamente distintas, a educação e a administração. O universo da educação, a linguagem, os conceitos abstratos são um campo novo de conhecimento para o administrador. A se ver desafiado pelas exigências de mercado e pelas necessidades de aperfeiçoamento de sua formação, os educadores em administração terão de transpor esta barreira disciplinar entre os dois universos, desafio este enfrentado no processo de pesquisa e escrita deste trabalho.

Em termos de futuras pesquisas sugere-se a construção de pesquisa conclusiva baseada na geração de hipóteses de correlação entre as variáveis categóricas (fonte de financiamento, região onde se localiza, etc.) e os níveis de interdisciplinaridade apresentados pelas IEs no Brasil. 


\section{REFERÊNCIAS}

American Association for Higher Education. Scanning the Environment: AAHEA's President Reports on Trends in Higher Education. AAHEA Bulletin, 1998.

ANTUNES, D.; THOMAS, H. The competitive (dis) advantages of European business schools. Long Range Planning, v. 40, n. 3, p. 382-404, 2007.

BAIRON, S. Interdisciplinaridade: educação, história da cultura e hipermídia. São Paulo: Futura, 2002.

BENNIS, W. G.; O’TOOLE, J. How Business Schools Lost their Way. Harvard Business Review, v.83, n.5, p. 96-104, 2005.

BRUUN, H. Promoting interdisciplinary research. Helsinki: Publications of the Academy of Finland, 2005.

CEZARINO, L. O. Mensuração da interdisciplinaridade nos cursos de graduação em administração. 2013. Tese (Doutorado em Administração) - Faculdade de Economia, Administração e Contabilidade, Universidade de São Paulo, São Paulo, 2013.

CEZARINO, L. O.; HEARNOUX JUNIOR, F.; CORREA, H. L. Organization performance evaluation using system thinking: a study in Brazilian chemical organizations models. Systemic Practice and Action Research, v. 25, n. 1, p. 81-92, 2012.

CORNUEL, E. The Role of Business Schools in Society. Journal of Management Development, v.24, n.9, p. 819-29, 2005.

COOPER, D.; SCHINDLER, P. S. Métodos de Pesquisa em Administração. Porto Alegre: Bookman, 2003.

DEMAJOROVIC, J.; DA SILVA, H. C. O. Formação interdisciplinar e sustentabilidade em cursos de administração: desafios e perspectivas. Revista de Administração Mackenzie, v. 13, n. 5, p. 39, 2012.

DEMO, P. Pesquisa: princípio científico e educativo. São Paulo: Cortez, 2001.

DIAS, T. M. da C. "Inovações no Processo de Ensino/Aprendizagem da Administração: Interdisciplinaridade versus Interdisciplinaridade".

CAMPOS, G.; DOMITTI, A. C. Apoio matricial e equipe de referência: uma metodologia para gestão do trabalho interdisciplinar em saúde. Cad. saúde pública, v. 23, n. 2, p. 399407, 2007.

ETGES, N. J. Ciência, interdisciplinaridade e educação. Interdisciplinaridade: para além da filosofia do sujeito, v. 3, n.1, p. 51-84, 1995.

FAZENDA, I.C. Práticas interdisciplinares na escola. São Paulo: Cortez, 1991.

FAZENDA, I. C. Virtude da força nas práticas interdisciplinares. São Paulo: Papirus, 1999.

FAZENDA, I. C. Interdisciplinaridade: história, teoria e pesquisa. São Paulo: Papirus, 2006

FERREIRA, S. L. In: FAZENDA, I.C. (coord.). Práticas Interdisciplinares na Escola. São 
Paulo: Cortez, 1991.

FIORETIN, M.; DOMINGUES, M. J. Interdisciplinaridade no curso de ciênciascontábeis: um estudo na universidade de passo fundo do estado do Rio Grande do Sul. Anais do XIV SEMEAD. São Paulo, 2011.

FOUREZ, G. A construção das ciências: introdução à filosofia e à ética das ciências. São Paulo: Unesp, 1995.

GUSDORF, G. Passé, present, avenir de la recherche interdisciplinaire. Revue Internationale de Sciences Sociales, v. 29, n.4, p. 627-648, 1977.

GUSDORF, G. Georges. Conhecimento interdisciplinar. Interdisciplinaridade: Antologia. Porto: Campo das Letras, 2006.

HAMBRICK, D. C. What if the Academy Actually Mattered? Academy Of Management Review, v.19, n.1, p.11-16, 1994.

HAY, M. Business Schools: A New sense of Purpose. Journal of Management Development, v.27, n.4, p. 371-378, 2008.

HUKKINEN, J. I. Hybrid expertise: Transdisciplinary excursions in Lapland, 2012.

HUUTONIEMI, K.; KLEIN, J.T.; BRUNN, H., HUKKINEN, J. Analyzing interdisciplinarity: Typology and indicators. Research Policy, v.39, n.1, p. 79-88, 2010.

JAPIASSU, H. Interdisciplinaridade e patologia do saber. Rio de Janeiro: Imago, 1977.

KAYO, E. K.; SECURATO, J. R. Método Delphi: fundamentos, críticas e vieses. Cadernos de pesquisa em Administração, v. 1, n. 4, p. 51-61, 1997.

KELLY, J. S. Wide and narrow interdisciplinarity. The Journal of General Education, v. 45, n.1, p. 95-113, 1996.

KLEIN, J. T. Interdisciplinarity: history, theory, and practice. Detroit: Wayne State University, 1990.

LENOIR, Y. Três interpretações da perspectiva interdisciplinar em educação em função de três tradições culturais distintas. Revista Científica e-curriculum, v.1, n.1, 2005.

LÜCK, H. Pedagogia interdisciplinar: fundamentos teórico-metodológicos. Petrópolis: Vozes; 2003.

MINAYO, M.C. de S.; SOUZA, ER de. Violência e saúde como um campo interdisciplinar e de ação coletiva. História, Ciências, Saúde, v. 4, n. 3, p. 513-531, 1998.

MORIN, E. A cabeça bem feita. Rio de Janeiro: Bertrand Brasil, 2000.

Morin, E. Introdução ao pensamento complexo. Porto Alegre: Sulina, 2007.

NICOLESCU, B. Educação e transdisciplinaridade. Organização das Nações Unidas para a Educação, a Ciência e a Cultura, Representação no Brasil, 2001.

NICOLINI, A. Educação em administração. Qual será o futuro das fábricas de administradores? Revista de Administração de Empresas, v. 43, n. 2, p. 44-54, 2003.

PARKER, L.; GUTHRIE, J. Business Schools in an Age of Globalization. Accounting, 
Auditing \& Accountability Journal, v.23, n.1, p. 5-13, 2010.

PIAGET, J. Interdisciplinarity: problems of teaching and research in universities, p. 127-139, Paris: OECD, 1972.

POLDOLNY, J. M. The buck stops (and starts) at business school. Harvard Business Review, v. 87, n. 6 , p. $62-67,2009$.

POMBO, O. Problemas e perspectivas da interdisciplinaridade. Revista de Educação, v.4, n.1, p. 2, 1994.

RICHARDSON, R. J. Pesquisa social: métodos e técnicas. São Paulo: Atlas, 1985.

ROSSINI, F. A.; PORTER, A. L. Frameworks for integrating interdisciplinary research. Research Policy, v.8, n.1, p. 70-79, 1979.

SANDSTRÖM, U. Interdisciplinarity—An Analysis. Stockholm: Swedish Research Council, 2005.

SERVA, M.; ANDION, C. Teoria das organizações e a nova sociologia econômica: um diálogo interdisciplinar. Revista de Administração de Empresas, v. 46, n. 2, p. 10-21, 2006.

SYVERTSEN, C. What is the Future of Business School? European Business Review, v. 20, n. 2, p. 142-151, 2008

ZELL, D. The Market-driven Business School: Has the Pendulum Swung too Far? Journal of Management Inquiry, v.10, n.4, p. 324-40, 2001. 


\section{DADOS DOS AUTORES}

\section{LUCIANA ORANGES CEZARINO^lcezarino@gmail.com}

Doutora em Operações pela FEA-USP

Instituição de vinculação: Universidade Federal de Uberlândia

Uberlândia/MG - Brasil

Áreas de interesse em pesquisa: Interdisciplinaridade e práticas sustentáveis nas operações.

^Rua João Naves de Ávila, 2121-Bloco 5M sala 102 Santa Mônica 38400-902 Uberlândia/MG

\section{HAMILTON LUIZ CORRÊA hamillco@usp.br}

Doutor em Administração Geral pela FEA-USP

Instituição de vinculação: Universidade de São Paulo

São Paulo/SP - Brasil

Áreas de interesse em pesquisa: Avaliação do desempenho global, Ensino e Pesquisa em Administração. 